\title{
Las bañistas de Raquel Forner: mujeres modernas
}

\author{
Georgina G. Gluzman \\ Consejo Nacional de Investigaciones Científicas y Técnicas \\ Universidad Nacional de San Martín
}

\section{INTRODUCCIÓN}

La literatura artística argentina, desde los primeros textos tendientes a presentar una historia unificada del desarrollo artístico local, ha ido construyendo un repertorio de artistas notables donde la presencia femenina es escasa. En efecto, sólo un puñado de artistas mujeres ha logrado una inserción, relativamente estable, en estos relatos. La inscripción de las mujeres en ellos no es solamente escasa sino también sumamente compleja. Como ha señalado Griselda Pollock, es posible pensar que las mujeres artistas que tienen cierto renombre no son canónicas (es decir, no proveen un referente de grandeza), sino simplemente célebres o sensacionales. ${ }^{1}$ En efecto, en muchas de ellas acceden a cierto renombre a partir no de la comprensión y valorización de su obra, sino del sensacionalismo. ${ }^{2}$ En el caso argentino, existen varias leyendas artísticas, entre las que se ha1la la pintora Raquel Forner (1902-1988). Como veremos, su inserción, aunque novedosa en muchos sentidos, se ha basado en su supuesta sensibilidad exacerbada y ha ocultado otras facetas de su trabajo.

La reconocida pintora ha ocupado un lugar preferencial en los relatos sobre la modernización plástica de la década de 1920 desde épocas muy

\footnotetext{
1 Pollock 1999: 99.

2 Pollock 1999: 97.
} 
tempranas. En efecto, ya desde el relato inaugural del crítico e historiador del arte José León Pagano, Forner apareció imbuida de cualidades supuestamente excepcionales. En El arte de los argentinos de 1940 se expresaba de este modo: "Varonil, impetuosa, huía de lo agraciado, como si temiese incluir en blanduras desprovistas de vigor". ${ }^{3}$ A partir de su ingreso a esta narrativa fundacional, la artista se convertiría en una de las escasas presencias femeninas permanentes en las historias generales del arte en la Argentina.

Forner había irrumpido con gran fuerza en el escenario artístico porteño. Su representación de sí y el modo en que su figura fueron registrados por la crítica inauguraron un nuevo modo de ser mujer artista en el escenario porteño. En 1924, en su primera presentación pública, Forner presentó obras como Sol y Mis vecinas, obra distinguida con el Tercer Premio en el certamen nacional de ese año. Esta recompensa, la primera entre las tres mayores obtenida por una mujer, nos habla de los nuevos y complejos lugares abiertos a las artistas durante la década de 1920.

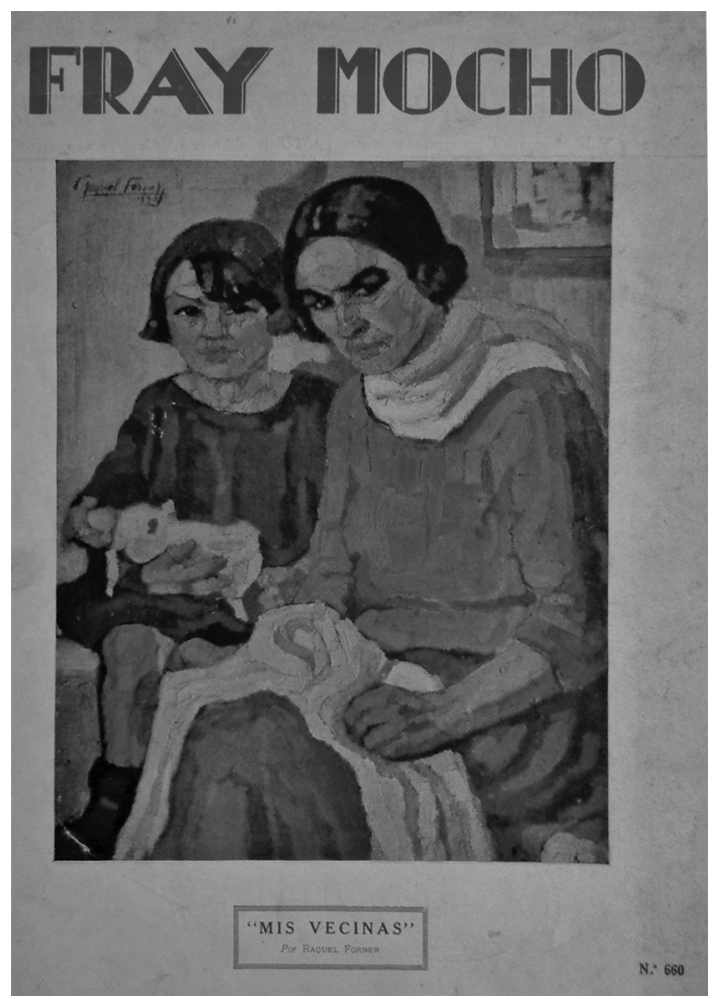

[Fig. 1. Raquel Forner, Mis vecinas, 1924, destruida. Tomada de Fray Mocho, 1924.]

3 Pagano 1940: 361. 
En 1925 uno de sus envíos al Salón Nacional fue rechazado por los miembros del jurado pertenecientes a la Comisión Nacional de Bellas Artes. Se trataba de una mujer moderna, de mirada decidida y postura desafiante. El hecho no pasaría desapercibido por la prensa comprometida con la renovación artística.

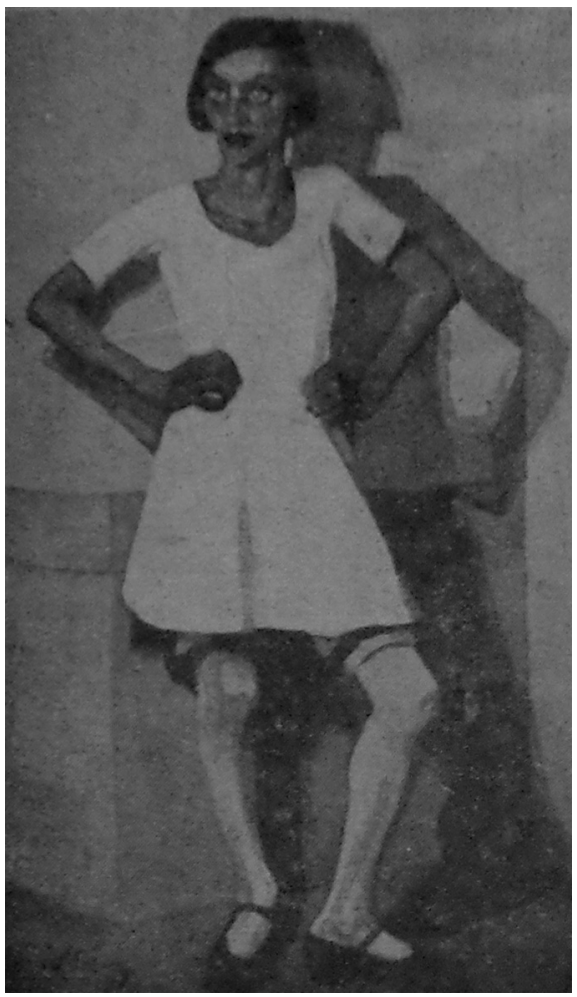

[Fig. 2. Raquel Forner, Figura, 1925, destruida. Tomada de Martín Fierro, 1925.]

Este episodio motivó la publicación de un suelto en la célebre revista Martín Fierro, donde se cuestionaba el derecho del jurado de rechazar la obra y se afirmaba que la misma era "de una generación que tiene sensibilidad distinta y una verdad mejor, porque es más nueva". ${ }^{4} \mathrm{El}$ artículo, que reproducía la obra en cuestión, calificaba a Forner de "niña" de "ojos nuevos". ${ }^{5}$ Comentarios como este cimentarían la fortuna crítica de Forner y la harían acreedora de un lugar

${ }^{4}$ Marechal 1925: 177.

5 Marechal 1925: 177. Sobre este suelto, Altamirano y Sarlo afirmaron: "De todos los artículos y sueltos que se publican sobre este tema en Martín Fierro, quizás el más contaminado de radicalismo sea 'Un cuadro rechazado', típica pieza de la tradición vanguardista del refusé: el jurado, se afirma, no tiene derecho a juzgar, porque no entiende las obras producidas a partir de una sensibilidad mejor 'porque es más nueva'.” Altamirano, Sarlo 1997: 149. 
en prácticamente todas las historias generales del arte. En efecto, Forner ingresaría como una presencia insoslayable dentro el grupo de los artistas renovadores de las décadas de 1920 y 1930. Junto a ella se situaría una sola mujer más: Norah Borges.

Sin embargo, la inscripción de Forner en las historias del arte argentino es sumamente ambivalente. Por un lado, está siempre presente su caracterización como artista de mérito, un hecho que la aleja de la figura de Lola Mora, cuya inclusión se vincula más nítidamente con un discurso de víctima solitaria en un campo cultural pretendidamente hostil. Pero, por otro lado, la dimensión dramática e incluso heroica de Forner es absolutamente esencial. Guillermo Whitelow, por ejemplo, ha señalado: "No estaría desencaminado quien considerase la obra pictórica de Raquel Forner como un despliegue ininterrumpido de dramáticos acontecimientos y de extrañas premoniciones". ${ }^{6}$ El crítico de arte continuaba destacando que "En una primera fase de su desarrollo, hasta llegar a las Series del Espacio, su preocupación giró en torno al destino de la humanidad".?

La etapa inicial a la que Guillermo Whitelow hacía referencia no era definida con precisión y parecía abarcar sólo las obras desde mediados de la década de 1930. En efecto, se omitían las obras tempranas de Forner, previas a su viaje de formación a Europa. Son precisamente estas obras las que nos proponemos analizar.

Este trabajo tiene tres objetivos principales. En primer lugar, estudiaremos cómo la historia y crítica del arte han privilegiado el análisis de las Series de España y del drama, marginando otras producciones de la artista. En segundo lugar, examinaremos la imaginería femenina desplegada por Raquel Forner en sus obras durante el período comprendido entre 1924 y 1929, prestando particular atención a las bañistas de 1928 y 1929. En tercer lugar, exploraremos los modos en que la iconografía de la mujer moderna permeó la producción de otras artistas contemporáneas, poniendo de manifiesto los modos en que las artistas del período tematizaron los nuevos lugares sociales abiertos a las mujeres mediante el caso de Lucrecia Moyano. En este sentido, analizaremos también algunas apariciones del sumamente frecuente tema de la bañista en la cultura visual del período. Nuestra hipótesis de partida es que el compromiso antifascista de Forner ha ocultado otras facetas de su trayectoria, en particular su interés en la iconografía de la mujer moderna, que nos proponemos indagar.

\footnotetext{
${ }^{6}$ Whitelow 1980: 7.

7 Whitelow 1980: 7.
} 


\section{Mujeres dolientes: unA ICONOGRafía FEMENina de RaQuel Forner}

La Serie de España (desarrollada entre 1937 y 1939) y la Serie del drama (entre 1939 y 1946) son sin duda las obras mejor conocidas y estudiadas de la vasta producción de Forner. Como señaló Diana Wechsler, "están atravesadas por lo patético instalado en un paisaje trágico y violento que desgarra a los personajes". ${ }^{8}$ Ya Pagano había descripto las obras desde finales de la década de 1930 como imbuidas de un profundo contenido emocional. Mujeres del mundo, en tal sentido, era presentada como "un lienzo mayor en todo sentido". 9

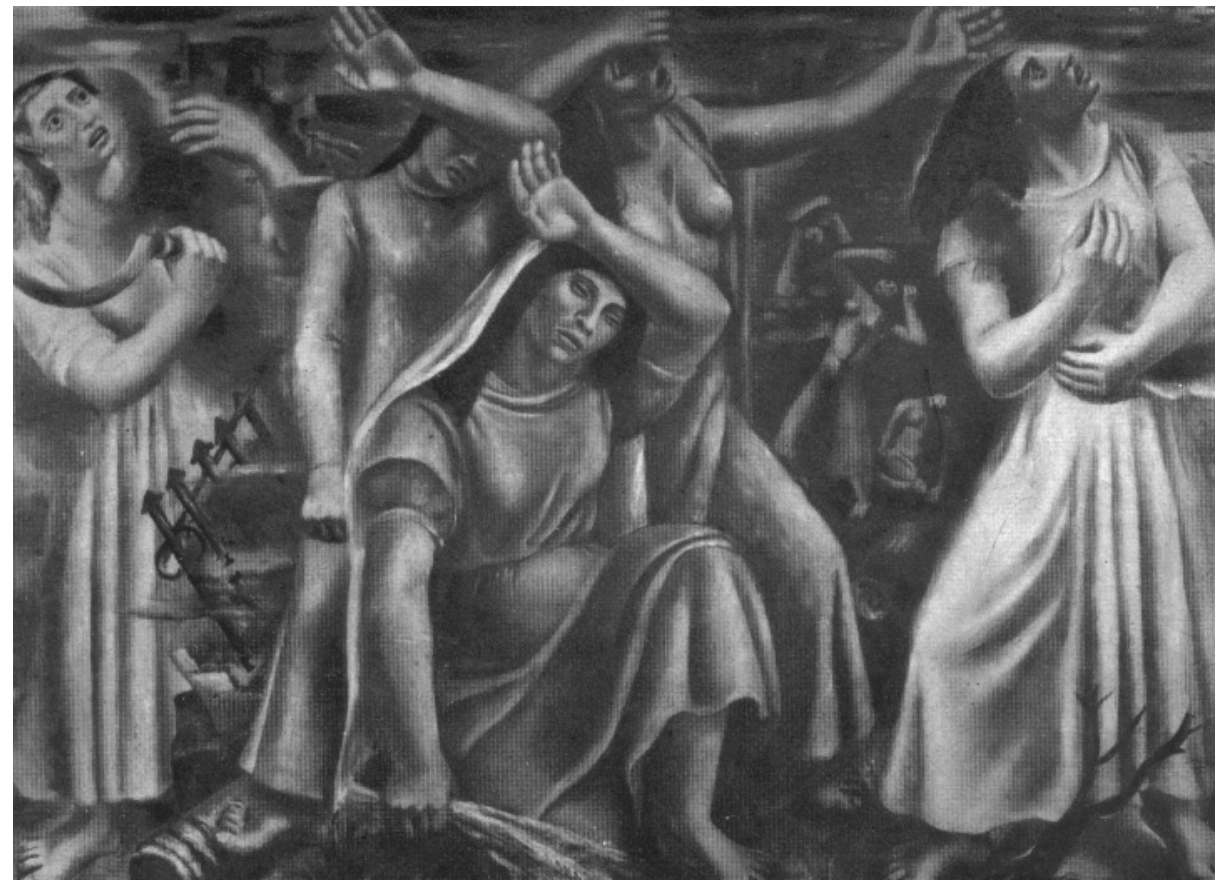

[Fig. 3. Raquel Forner, Mujeres del mundo, 1938, óleo sobre tela, 170 x 238 cm, Fundación Forner-Bigatti, Buenos Aires. Tomada del Archivo José León Pagano, Museo de Arte Moderno de Buenos Aires.]

Ya en 1942 Geo Dorival, en el volumen que la editorial Losada le dedicó a la artista, comenzaba su análisis de la trayectoria de Forner de este modo: "La pintura de Raquel Forner refleja el drama de muchos artistas contemporáneos". ${ }^{10}$

\footnotetext{
8 WeChSLER 2010: 817.

9 Pagano 1940: 362.

10 DORIVAL 1942: 5.
} 
De este modo, desde el mismo inicio de su monografía situaba a la artista dentro de un terreno determinado: la realización de imágenes de "hondo contenido y eficaz capacidad persuasiva". ${ }^{11}$ Su pintura se dirigía hacia el "hombre humilde atormentado por calamidades que no desea ni provoca". ${ }^{12}$ Geo Dorival mencionaba, al pasar, su producción temprana: "Cuando, en un solo momento quiso hacer suyo el sentido de la juventud gozosa, de su paleta salieron tonos de tristeza". ${ }^{13}$ Con estas palabras, quedaba saldado el problema de su obra inicial: demostraba abatimiento aun en temas que debían tener matices felices. La sensibilidad extrema de la artista, un topos de la literatura forneriana, aparecía con claridad en este pasaje.

En 1946 se publicaba en la revista Qué Sucedió en 7 Días un interesante artículo sobre la producción de Forner. Allí, se la describía como la "pintora de la mujer doliente". ${ }^{14}$ A continuación, se destacaba que Forner "se descubrió a sí misma en el shock psicológico provocado por la guerra de España" ${ }^{15}$ Asimismo, se señalaba que "la mujer, bajo cien formas, se convirtió en protagonista de sus cuadros". ${ }^{16}$ Textos como este cimentaron el matiz particular que adquirieron estas series y el olvido de sus incursiones previas en el terreno de la construcción de una iconografía femenina, que tuvo un carácter absolutamente diferente.

Es necesario destacar que esta obliteración también responde a una intención de la propia artista y a su sentir en torno a la importancia de su producción de intención antifascista. En este sentido, en una entrada de su diario de noviembre de 1939 Forner escribía:

En setiembre del 18 al 30 expuse en Müller una serie de trabajos que expresan mi sentir. Son gritos de protesta, contra todo lo que está pasando en el mundo. Gritos de angustia ante el dolor del mundo; ante el atropello de mujeres y niños, ante el atropello de las fuerzas espirituales. Porque no solamente se destrozan cuerpos y seres, es todo: la inteligencia, la dignidad, el arte que se destroza y humilla... ${ }^{17}$

Además de este lugar central que la misma artista le otorgaba a estas series, una de las obras que la integraban, El drama, obtuvo el Primer Premio de Pintura en el Salón Nacional de 1942. De este modo, las series recibieron un

11 Dorival 1942: 6.

12 Dorival 1942: 7.

${ }^{13}$ Dorival 1942: 7.

${ }^{14}$ Qué Sucedió en 7 Días 1946: 34.

15 Qué SuCEDió en 7 Días 1946: 34.

${ }^{16}$ Qué SuCEDió en 7 Días 1946: 34.

17 Citada en: Whitelow 1998: 16. 
fuerte espaldarazo e ingresaban en el Museo Nacional de Bellas Artes, un espacio de indudable legitimación en el campo artístico argentino.

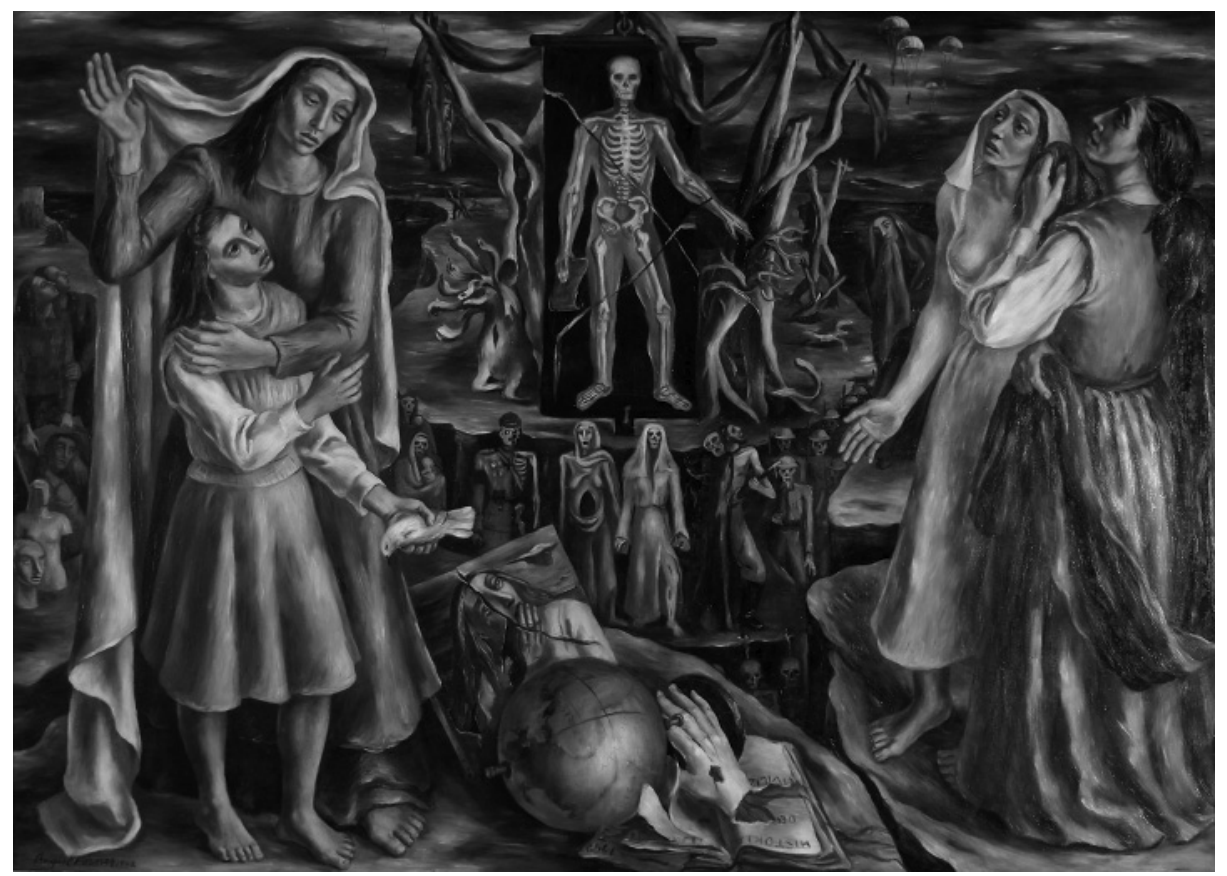

[Fig. 4. Raquel Forner, El drama, 1942, óleo sobre tela, 126 x 174 cm, Museo Nacional de Bellas Artes, numero de inventario 6401. Adquisición de la Comisión Nacional de Bellas Artes (1942).]

La centralidad de estas series en los estudios sobre Forner fue indiscutible a partir de este momento: la mayor parte de los análisis sobre su obra la consideran de modo detenido y, hasta cierto punto, excluyente. Diversas investigadoras actuales, entre las que se ha destacado Diana Wechsler, han profundizado en esta problemática. En tal sentido, Wechsler destaca que la mujer en la Serie de España es una figura compleja: "doliente, firme y poderosa a la vez, aparece como testigo del presente y motor para un cambio posible". ${ }^{18}$

18 WeChSLER 2003: sin paginar. 


\section{OtRAS PROTAGONISTAS: LAS MUJERES MODERNAS Y LAS BAÑISTAS}

Cuando Forner recibió el prestigioso Premio Palanza, en el diario La Prensa se hacía un repaso por los inicios de la trayectoria de la artista. Allí se especificaba que "la inclinación hacia los temas humildes" formaba parte de su carrera desde $1924 .{ }^{19} \mathrm{El}$ anónimo articulista no indicaba cuáles eran las características precisas de estos "temas humildes": el proceso de ocultamiento de la primera etapa de la producción de Forner, que siguió otros caminos a su obra más conocida y resulta sumamente interesante, estaba ya claramente consolidado. Sobreviven muy pocas obras tempranas de Forner, pues la artista destruyó gran parte de su producción previa a $1932 .{ }^{20}$ Esta es, tal vez, una de las razones detrás de la escasa atención que han recibido sus primeras intervenciones. En efecto, la mayor parte de las obras que analizaremos no han podido ser halladas ni en colecciones públicas o ni en colecciones privadas. Las reproducciones aparecidas en catálogos y en la prensa periódica ilustrada resultan fundamentales para la reconstrucción de este momento temprano de Forner.

Son pocos los historiadores del arte posteriores a la década de 1920 que han siquiera mencionado estas producciones. Al referirse a sus obras tempranas, Pagano señalaba: "Visión, técnica, asuntos, contenido espiritual todo la coloca en un plano de recio espíritu viril". ${ }^{21}$ Sin embargo, aquí buscamos explorar otra idea: Raquel Forner se acercó a la representación de la nueva feminidad de su tiempo mediante una apropiación táctica de un tema clásico de la historia del arte.

El análisis de los catálogos y reseñas de exposiciones, junto al estudio de una obra que ha sobrevivido, permite un acercamiento a uno de los temas centrales de la iconografía femenina temprana de Forner, centrada en las mujeres nuevas. En tal sentido, la muestra individual de 1928, realizada en la Galería Müller, incluyó óleos y dibujos con figuras, paisajes y naturalezas muertas. ${ }^{22} \mathrm{La}$ imagen de la mujer moderna, una iconografía que había comenzado a aparecer en la producción de artistas mujeres ya en la década previa, ocupó un lugar central. ${ }^{23}$ Por ejemplo, en Retrato Forner mostraba a una mujer reflexiva y de apariencia fuerte, con gestos intensos y manos fuertes.

\footnotetext{
19 LA PRENSA 1948: sin paginar.

20 Whitelow 1983: sin paginar.

21 Pagano 1940: 361.

22 Pagano 1928

${ }^{23}$ Gluzman 2016: 230-248.
} 


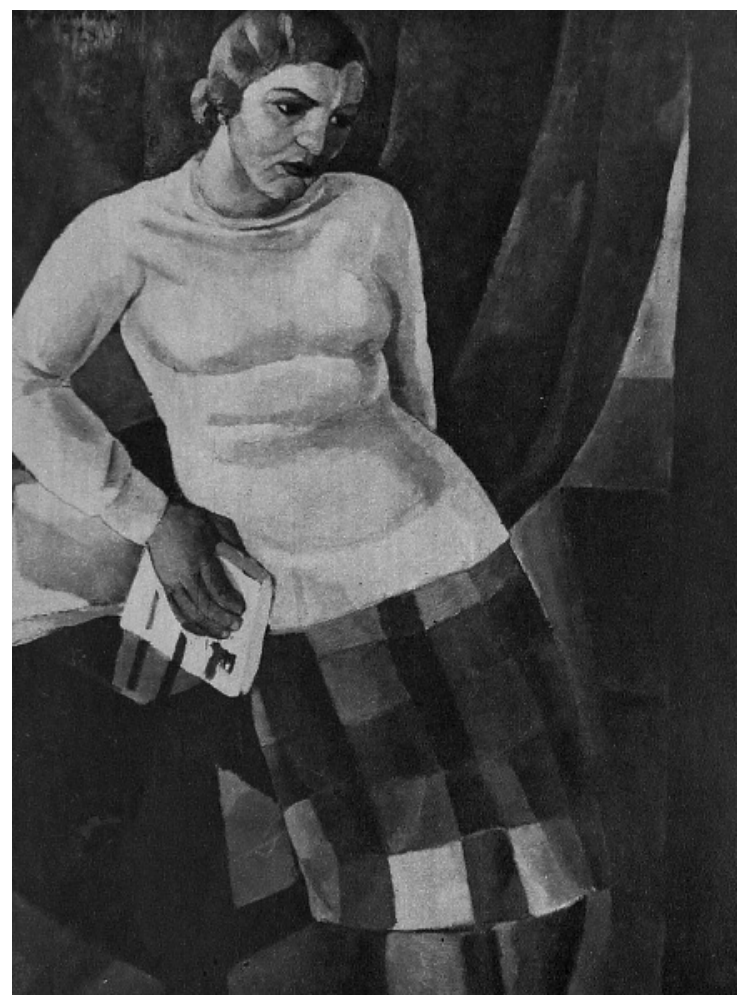

[Fig. 5. Raquel Forner, Retrato, ubicación actual desconocida. Expuesto en la exhibición individual en Galería Müller en 1928. Tomada de La Prensa, 1928.]

Desde las páginas del diario La Nación, José León Pagano se refirió a la muestra de Forner. Allí señaló la independencia frente al academicismo como marca esencial de la por entonces breve producción de la artista. ${ }^{24} \mathrm{El}$ "estremecimiento de la modernidad", en palabras del mismo Pagano, ingresaba de lleno al ambiente argentino y el crítico reconocía el rol central de Forner en el proceso. ${ }^{25}$ Del mismo modo, la crítica de arte y escritora Pilar de Lusarreta calificaba a Forner de "inteligente, trabajadora". ${ }^{26}$

En 1928 y 1929 Forner expuso algunas bañistas en el Salón Nacional, en el Nuevo Salón y en su presentación individual. No sabemos con exactitud qué obra expuso en su muestra de la galería Müller, pero sí tenemos la certeza de

\footnotetext{
24 Pagano 1928.

25 Pagano 1928.

${ }^{26}$ LUSARRETA 1929: 53.
} 
que incluyó una obra con esta iconografía, pues Atalaya destacó un "paisaje de playa con figura". ${ }^{27}$

Forner retomaba una temática clásica: aquella de las bañistas, mujeres indolentes y despreocupadas en el contexto de tomar un baño. El tema de los bañistas había tenido un amplio desarrollo durante el siglo XIX. Al respecto, Linda Nochlin ha señalado: "En la superficie nada parece menos problemático que la bañista decimonónica. Parece ser algo 'dado' dentro de la historia del arte: eterno, elevado, idealizado y, como tal, central para los discursos del gran arte. Sin embargo, se ha hecho obvio que el tema de la bañista es cualquier cosa menos algo 'dado', es lo opuesto a lo natural". ${ }^{28}$

Una de las bañistas de Forner fue expuesta en el Salón Nacional de 1928. La participación de Forner en el certamen fue elogiada por diversos críticos. En La Prensa se comentó:

señalaremos el cuadro 'Bañista' de Raquel Forner, obra de estructura vigorosa, refinadamente moderna en sus expresiones de plasticidad libre que la joven artista ha resuelto en esos ritmos oblicuos que presentan casi todos los cuadros expuestos actualmente en su muestra individual de la Galería Müller. ${ }^{29}$

En su crítica Pilar de Lusarreta señalaba que "la señorita Forner (...) presenta una bañista en 'maillot' violeta". ${ }^{30}$ En ambas reseñas se destacaba la modernidad de la figura. Como vimos, Pilar de Lusarreta llegaba incluso a comentar la prenda específica utilizada por la bañista de Forner. En efecto, lo que llamaba la atención era esta moderna pieza de baño.

Ampliando su interés hacia espacios no oficiales, la artista expuso también en el Nuevo Salón de 1929, un espacio de renovación plástica. La obra fue elogiada en La Razón: "Raquel Forner ofrece en un lienzo de playa, la evidencia de un sentido de la forma extraordinaria en un bello alarde de volúmenes" ${ }^{31} \mathrm{La}$ obra presenta a tres figuras femeninas en diferentes posiciones, formando un friso de mujeres modernas.

\footnotetext{
27 Atalaya 1934: 317.

${ }_{28}$ Nochlin 2006: 15. La traducción es nuestra.

29 LA Prensa 1928: sin paginar.

30 LuSARRETA 1928: 7.

${ }^{31}$ La Razón 1929.
} 


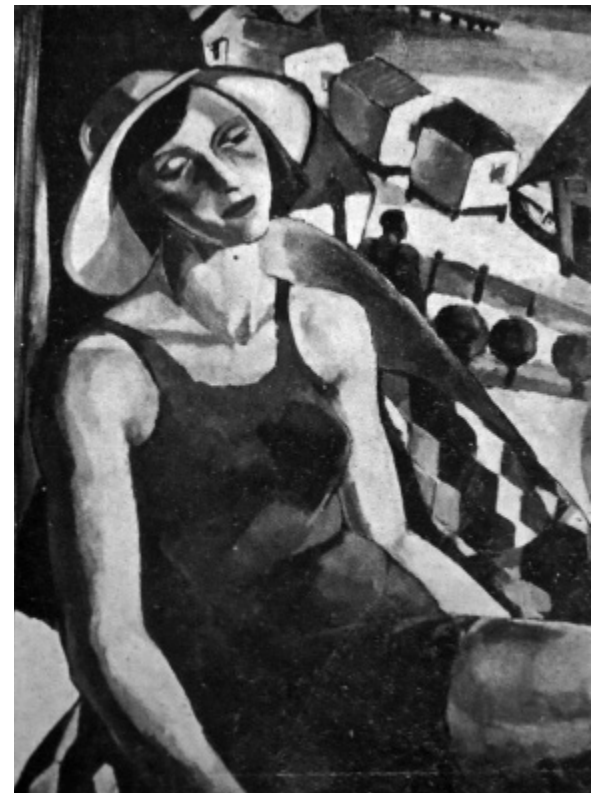

[Fig. 6. Raquel Forner, Bañista, ubicación actual desconocida. Expuesto en el Salón Nacional de 1928. Tomada del catálogo oficial.]

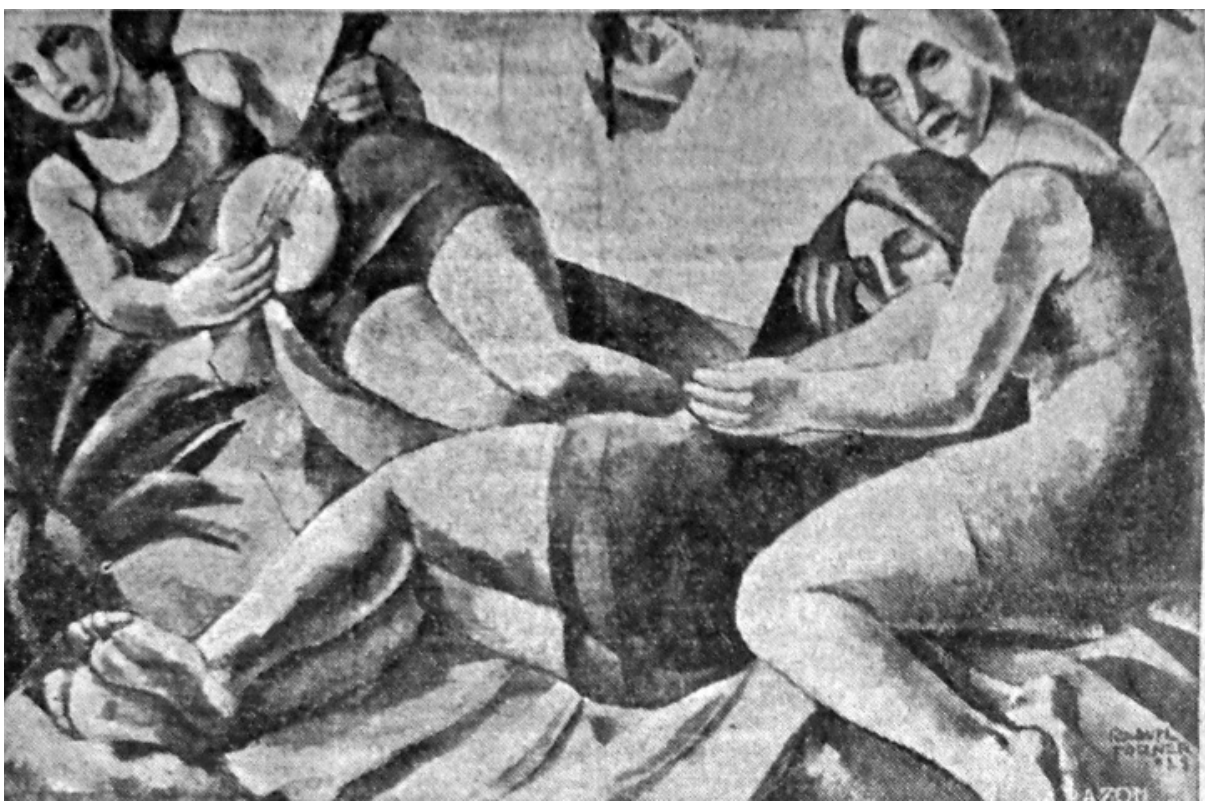

[Fig. 7. Raquel Forner, Composición, ubicación actual desconocida. Expuesto en el Nuevo Salón en 1929. Tomada de La Razón, 1929.] 
Existe apenas una obra conservada de esta serie: la Bañista del Museo Nacional de Bellas Artes, una de las pocas obras anteriores a su viaje a París que han llegado a nuestros días. Tal vez haya sido la misma bañista expuesta en su muestra individual. La obra representa a una joven en el primer plano. La sólida figura está desplazada hacia la derecha, dejando ver una naturaleza muerta y un fragmento de paisaje.

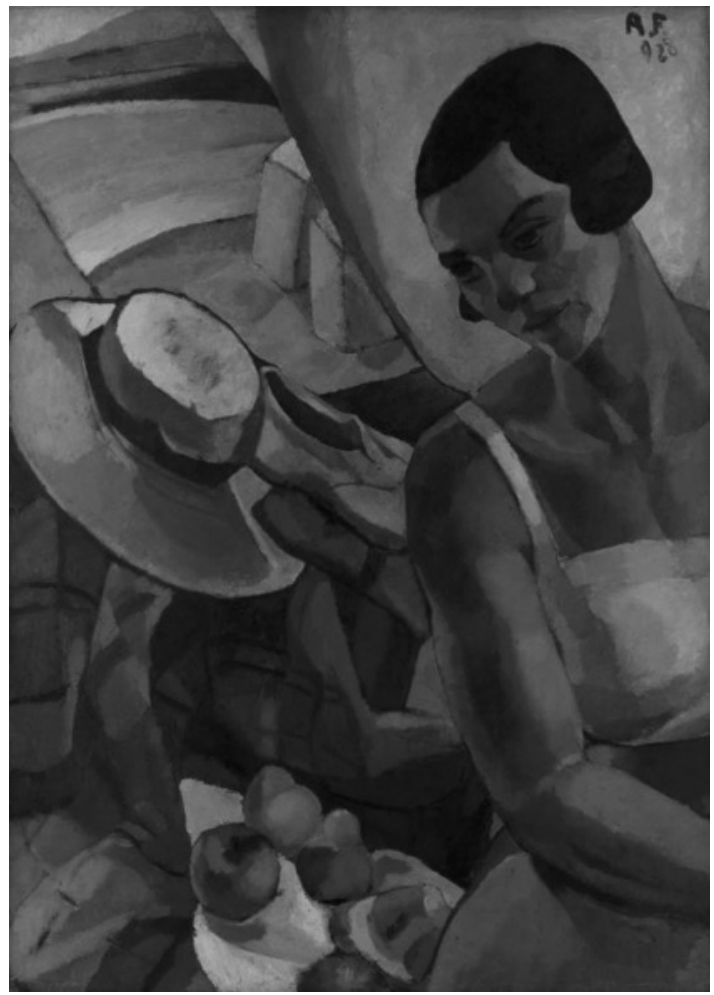

[Fig. 8. Raquel Forner, Bañista, 1928, óleo sobre cartón, 95 x 70 cm, Museo Nacional de Buenos Aires, número de inventario 6105. Donación de la Asociación Amigos del Museo (1935).]

Como vemos, Raquel Forner volvía una y otra vez en estos años sobre esta figura: la imagen de una mujer joven, con el pelo corto y vestida con una ropa específica: una malla a la moda. La misma imagen invadía contemporáneamente la cultura visual y la plástica, tanto a nivel local como internacional. En el ámbito europeo, por ejemplo, la imagen de la bañista fue tematizada por diversos artistas. La carga de modernidad se intensifica en obras como Quappi en azul en un bote, obra comenzada en 1926 por el artista alemán Max Beckmann 
(1884-1950). ${ }^{32}$ En ella, la esposa del artista se muestra en una moderna malla azul y con su gorra de baño.

En el terreno de las artes argentinas Raquel Forner no fue la única artista asociada a la renovación plástica que se ocupó de esta temática. En efecto, artistas célebres como Lino Enea Spilimbergo y Alfredo Guttero trabajaron esta iconografía, pero de un modo muy claramente anclado en la tradición de la historia del arte. Entre 1930 y 1931, por ejemplo, Spilimbergo realizó una pequeña témpera con el tema de las bañistas: las cuatro figuras están desnudas o semidesnudas, estableciendo un vínculo fuerte con la tradición de las bañistas atemporales a las que se refería Nochlin.

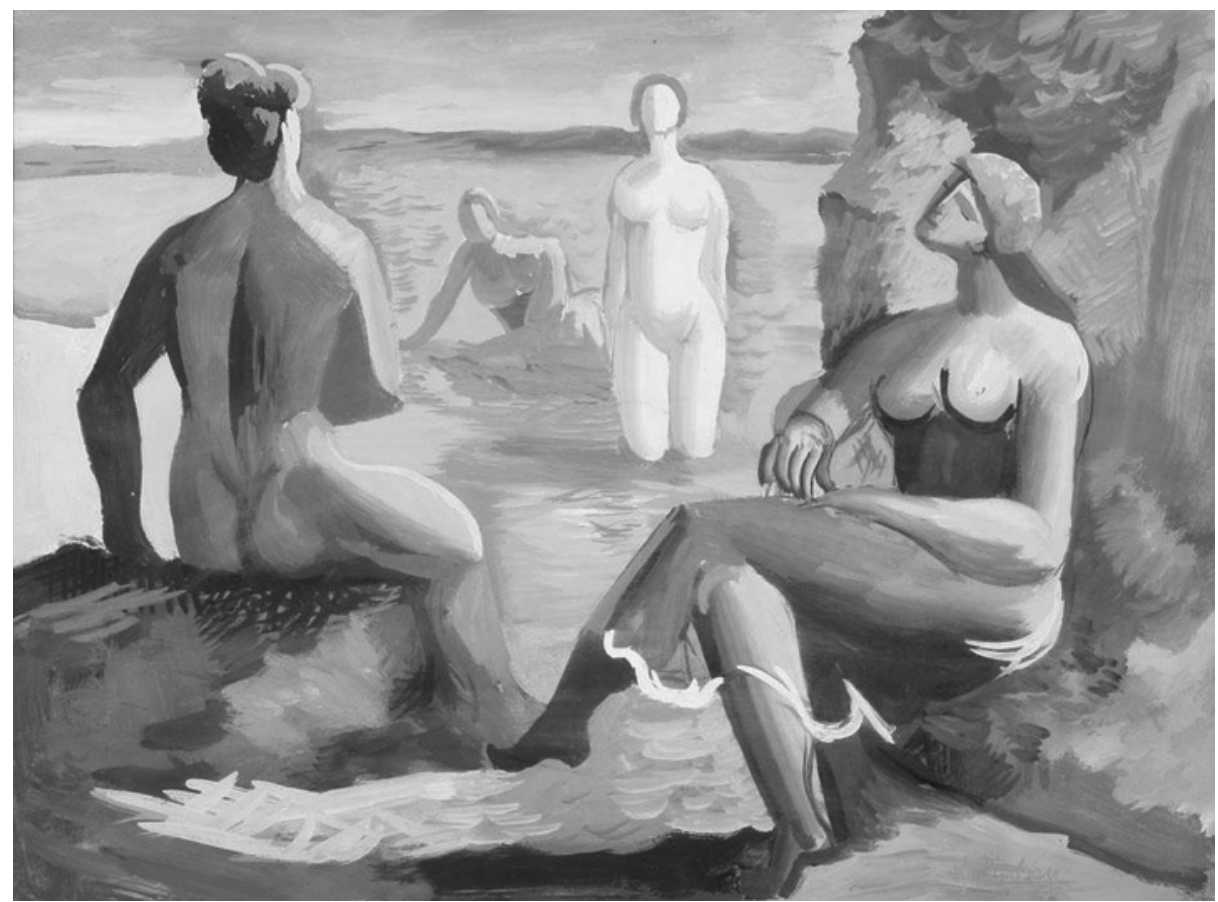

[Fig. 9. Lino Enea Spilimbergo, Las bañistas, circa 1930, témpera, 39 x $52 \mathrm{~cm}$, colección particular. ]

Por su parte, Alfredo Guttero realizó en 1928 su imponente yeso cocido En la playa. Desde las páginas de La Prensa se alabó la obra en estos términos:

Muy antiguo al par que muy moderno, clásico y contemporáneo al mismo tiempo, Guttero pinta con la amplitud de líneas y arabescos que

${ }^{32}$ Max Beckmann, Quappi de azul en un bote, 1926/1950, gouache sobre papel montado en cartón, 89,5 x $59 \mathrm{~cm}$, colección particular. 
ponían en los frescos los grandes decoradores italianos del siglo XVII. De los tres cuadros que expone, sólo uno es de figura: representa un grupo de bañistas sobre un fondo de mar azul, lleno de aire y sensaciones luminosas. Son cuatro desnudos de mujer, distintos de tonalidad los cuatro y resueltos en líneas de elegante distinción decorativa. ${ }^{33}$

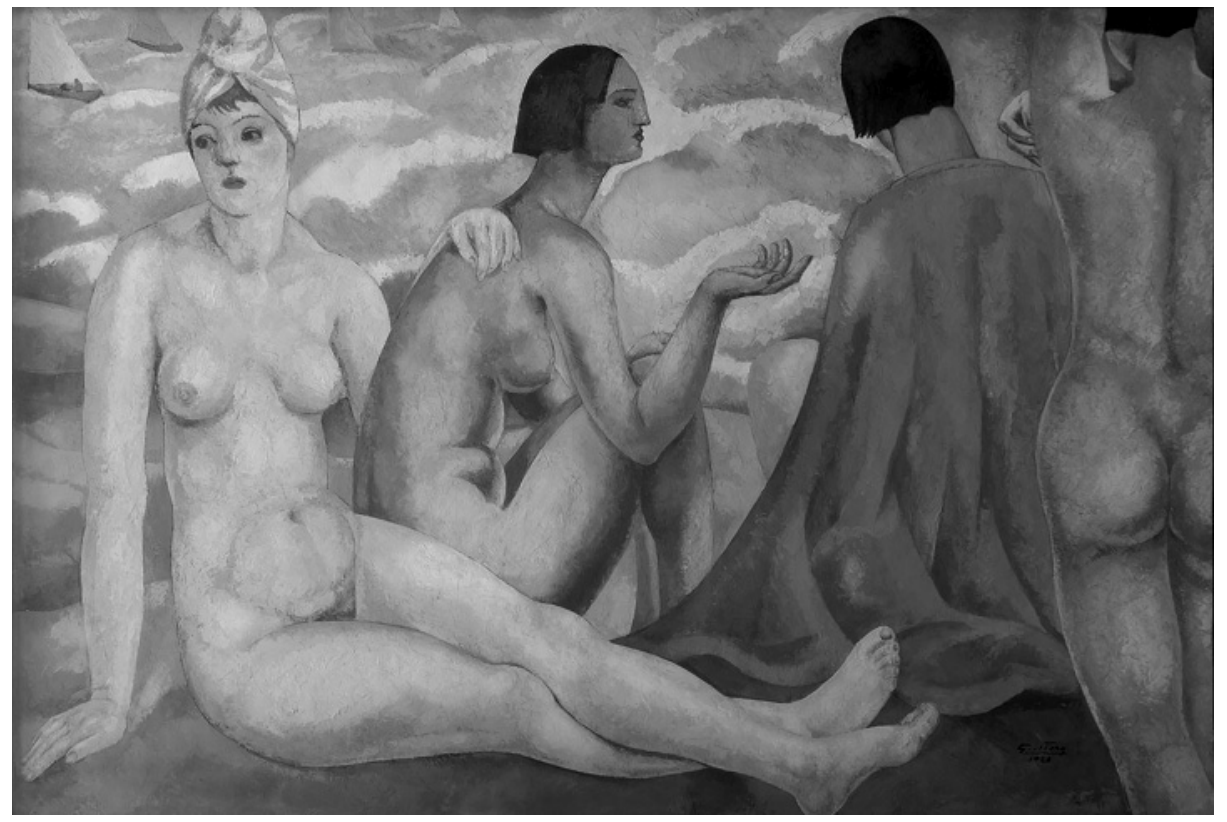

[Fig. 10. Alfredo Guttero, En la playa, 1928, yeso cocido sobre madera, 118,5 x 180,5 cm, Museo Franklin Rawson, San Juan.]

La reseña señalaba la modernidad plástica de la obra, al tiempo que delineaba su pertenencia a una tradición histórico-artístico profundamente arraigada. En efecto, la obra no remitía a los cambios en las costumbres y en la vestimenta femeninas contemporáneas, sino que la imagen permanecía firmemente anclada en un tema pictórico establecido. Pocos artistas, entre ellos Emilio Centurión, siguieron la línea de Forner.

${ }^{33}$ LA PRENSA 1928: sin paginar. 


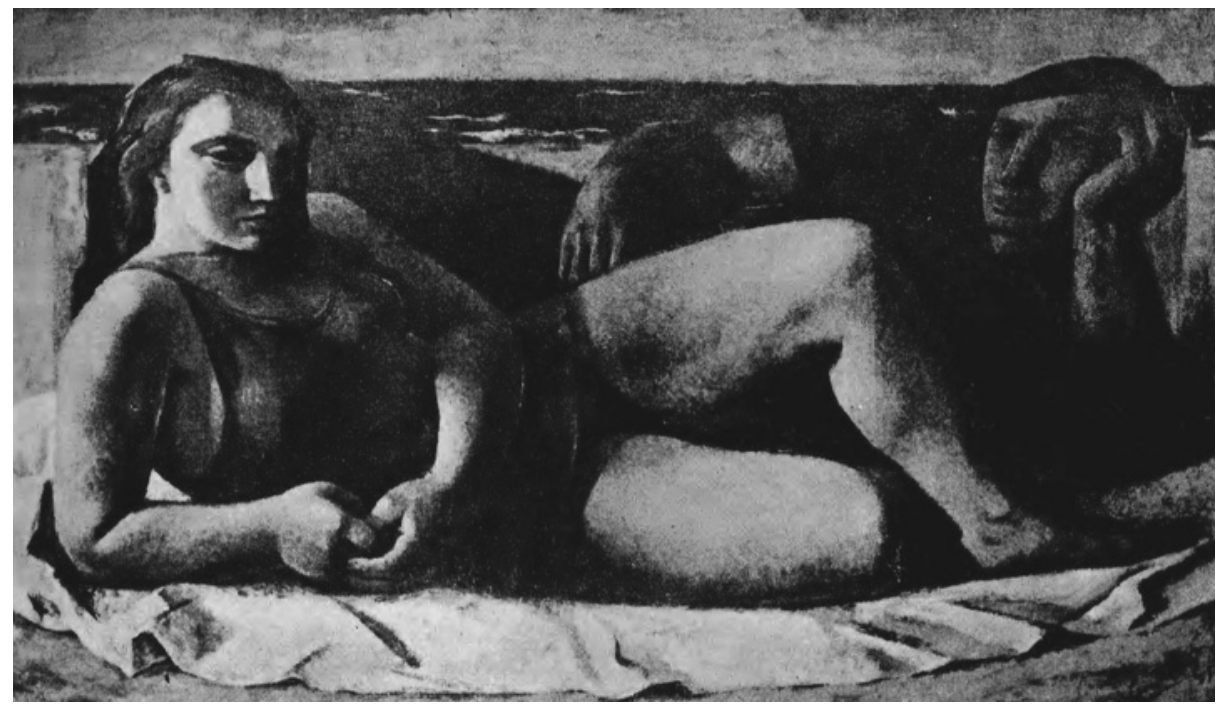

[Fig. 11. Emilio Centurión, Bañistas, ubicación actual desconocida.]

Raquel Forner fijaba su mirada en mujeres de clara apariencia moderna, anclando su régimen de representación en el presente inmediato. Dorival, según hemos visto, juzgaba a estas obras con palabras singulares: ellas exhibían "tonos de tristeza". ${ }^{34}$ En efecto, las mujeres modernas de Forner no son bañistas triunfantes, sino incómodas figuras en un espacio público que tendía a convertirlas en bellos objetos para el consumo visual, como veremos.

\section{BAÑISTAS, POR TODAS PARTES}

Una gran parte de las representaciones de bañistas que inundaron la cultura visual argentina en este período tenían un tono marcadamente positivo: era bueno para las mujeres pasar el tiempo en la playa y practicar diferentes actividades recreativas. Entre estas imágenes se hallaba, por ejemplo, la portada que la Revista Femenina de La Razón publicaba en 1933. La imagen muestra a una joven jugando con una pelota. Es una de las muchas representaciones textuales y visuales que en esta época tematizaron esta nueva faceta de las mujeres.

${ }^{34}$ Dorival 1942: 7. 


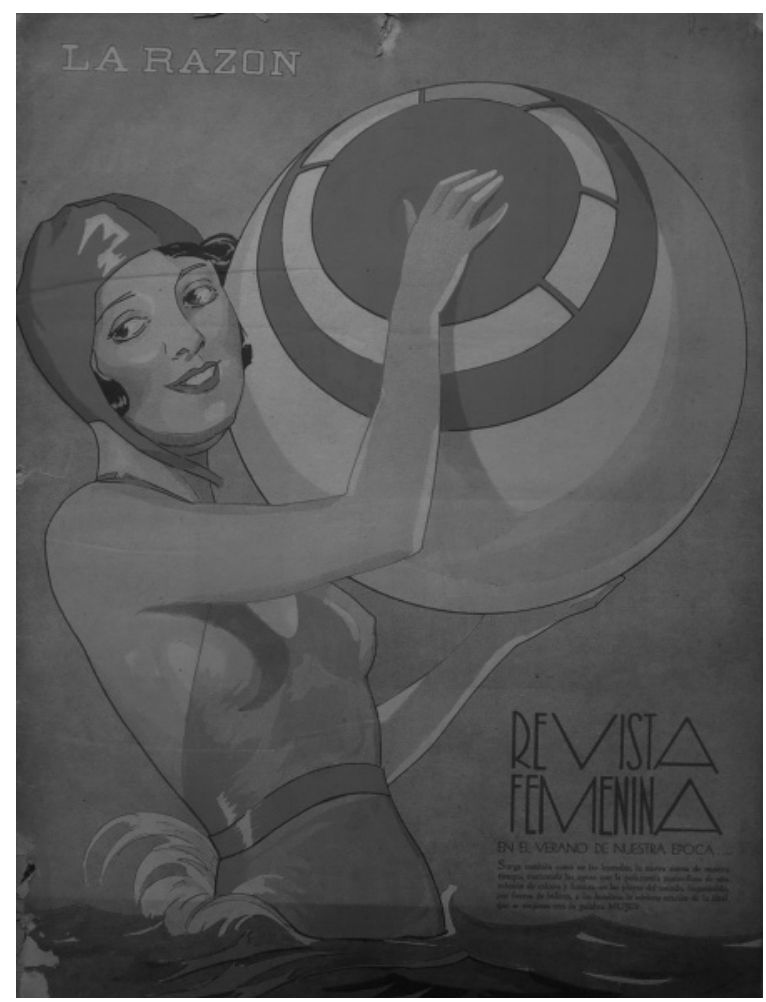

[Fig. 12. Portada de la Revista Femenina de La Razón, 30 de octubre de 1933.]

La presencia de las mujeres en el espacio público era, y continúa siendo, un tema controvertido. En particular, los nuevos trajes de baño estaban estrechamente asociados a una exposición indecente en el espacio público. Las quejas por el carácter excesivamente revelador de la moda de estos años inundaron la prensa. En tal sentido, la Revista Femenina del periódico La Razón reproducía en 1934 un artículo del escritor francés Clément Vautel (1876-1954) referido a la ropa de verano. Aunque señalaba que las mallas de baño estaban fuera de su crítica, el autor realizaba críticas generales a la piel de las piernas de las mujeres: "Pocas piernas son impecables: vellos superfluos que 'suprimidos definitivamente' por tal o cual producto, reaparecen como las barbas de los adolescentes; hay moretones inevitables, arañazos, manchas rojas, várices amenazados, hasta el mármol de Paros muestra sobre su blancura esas ventas azuladas". ${ }^{35}$

Así, el cuerpo femenino en público estaba sometido a la vigilancia y al escudriñamiento por parte de la mirada masculina, que buscaba convertirlo en un

35 VAUTEL 1934: 1. 
objeto de deleite visual. En efecto, las décadas de 1920 y 1930 estuvieron atravesadas por discursos tendientes a señalar los peligros que significaba para la belleza femenina el estar al sol. La publicidad de la crema de almendras Genz alertaba acerca de los cambios culturales y sus efectos sobre la piel: "La mujer moderna se ha emancipado de los velos, sombrillas y grandes sombreros que usaban sus abuelitas cuando se aventuraban al sol. Pero su cutis no ha seguido el cambio de la moda. Es tan sensible hoy a los efectos del sol como siempre, y debe cuidarse de sus quemaduras dolorosas". ${ }^{36}$

En un contexto marcado por la tensión entre nuevas actividades femeninas y nuevas formas de control social sobre el cuerpo de las mujeres, Forner aunó una aguda capacidad de observación y su interés por las mujeres contemporáneas. Junto a Forner, fueron muchas las artistas mujeres que tematizaron la figura de la bañista en estos años. Nos detendremos en dos ejemplos.

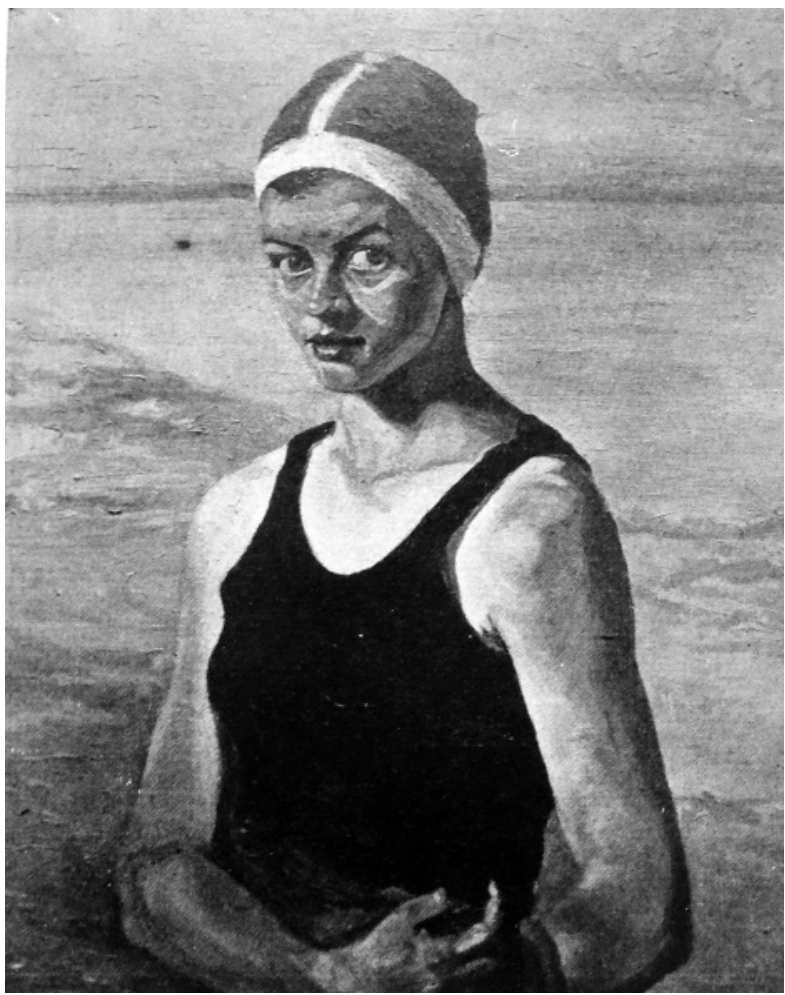

[Fig. 13. Hildara Pérez de Llansó, Bañista, ubicación actual desconocida. Expuesto en el Salón Nacional de 1930. Tomada del catálogo oficial.]

${ }^{36}$ El Hogar 1935: sin paginar. 
En primer lugar, hallamos una interesante obra de Hildara Pérez de Llansó, expuesta en el Salón Nacional de 1930. Absolutamente desplazada de las historias del arte en la Argentina, esta artista gozó de una visibilidad notable en el campo artístico desde sus primeros envíos al Salón. Su notable envío representaba a una joven bañándose, sumergida hasta la cintura en el agua. Su atuendo tiene todas las prendas modernas de la nadadora: malla de baño y gorra. La obra recibió críticas de tono variado, pero no fueron pocos los comentaristas que destacaron la calidad del lienzo. En La Prensa se pudo leer: "Señalaremos asimismo entre los buenos envíos del año, los tres lienzos con figuras que Hildara Pérez de Llanzó presenta en la segunda sala. De ellos no puede decirse sino que están magníficamente pintados en todos los sentidos que significa el pintar así un cuadro". ${ }^{37}$

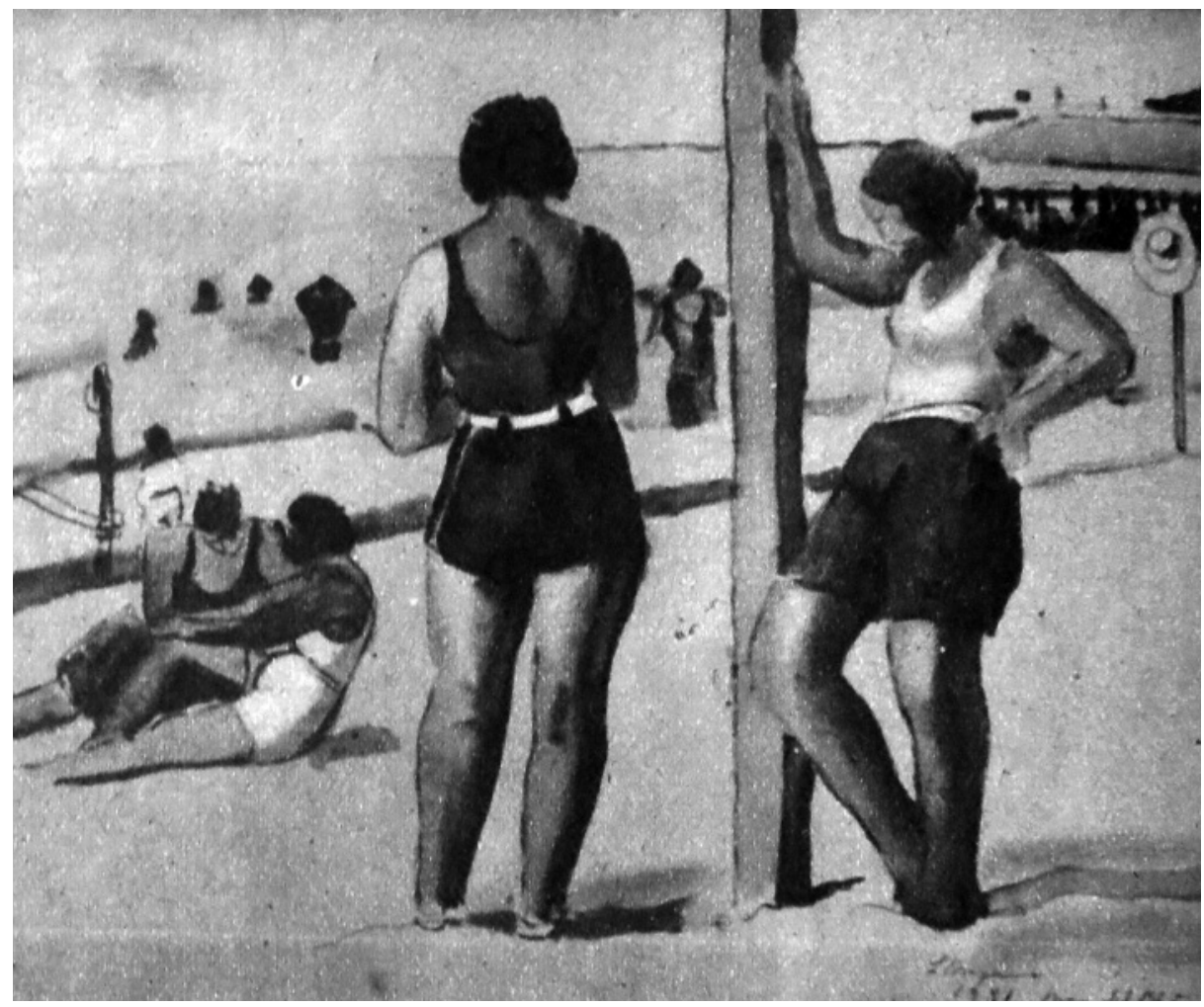

[Fig. 14. Lucrecia Moyano, En la playa, 1931, ubicación actual desconocida. Expuesto en el Salón de Acuarelistas, Pastelistas y Grabadores de 1928. Tomado de La Prensa, 1931.]

37 LA PRENSA 1930: sin paginar. 
Por otro lado, la pintora, ilustradora y diseñadora Lucrecia Moyano de Muñiz (1902-1998) también se inclinó por la temática de las bañistas. Aunque en la actualidad sea más recordada por su intensa actividad en el campo del diseño, Moyano se abocó en su juventud a la pintura e ilustración, llegando a exponer en el Salón Nacional (1925, 1927, 1928 y 1932) y en el Salón de Acuarelistas, Pastelistas y Grabadores en diversas oportunidades.

En 1931 expuso en este último espacio cinco acuarelas bajo el título de En la playa. Se trataba de apuntes rápidos realizados en las playas de Mar del Plata, ciudad a la que la artista estaba profundamente unida por vínculos familiares. Conocemos apenas uno de ellos, reproducido en La Prensa. La obra, de factura rápida y abocetada, muestra dos mujeres robustas en el primer plano. Tras ellas son visibles otras dos figuras femeninas. La artista no prestó atención a los rasgos individuales, sino que lo que parece interesarle singularmente es el tipo social femenino presente en las playas argentinas.

Pilar de Lusarreta criticaba duramente los envíos de la artista al salón de la Sociedad de Acuarelistas, Pastelistas y Grabadores: "En la [sala] V se ve otras tantas notas de Mar del Plata -dibujos acuarelados- de Moyano, obra ligera más a propósito para ilustrar una revista que para figurar en un salón". ${ }^{38}$ Moyano había en efecto publicado en la revista ilustrada El Hogar una serie de apuntes rápidos hechos en Playa Grande, donde había hecho confluir su atención a las mujeres en los balnearios con la fascinación que estas figuras ejercían en el público.

\section{A modo de Conclusión}

El énfasis en las mujeres dolientes ha ocultado las intervenciones de Forner en otros campos, uno de los cuales es su renovación de la imagen de la bañista, un tema del que participaban otras artistas de la época.

El ocultamiento ha llegado también a otras obras, como las presentadas en la Asociación Wagneriana en octubre de 1930 y que representaban escenas de África y Bolivia. Para Pagano, ellas se diferenciaban claramente de su estilo maduro de los últimos años ' 30 y la primera mitad de los '40: "El optimismo de estas visiones rápidas contrasta con su estado de ánimo actual”. ${ }^{39}$

La obliteración de la obra temprana de Raquel Forner, puesta en marcha por la propia artista, es capaz de revelar qué temas se han constituido como serios o importantes dentro de la tradición de la historia del arte. La producción

\footnotetext{
38 LuSARRETA 1931: 47.

39 Pagano 1940: 364.
} 
antifascista ocupó un lugar privilegiado frente a la aparente banalidad de las obras centradas en la mujer moderna. Sin embargo, su redescubrimiento permite acercarnos a un núcleo de prácticas cotidianas femeninas nuevas que en las décadas de 1920 y 1930 significaban modernidad y progreso. Quizás el temor a perder precisamente estas conquistas fuera un motor para las obras dolientes de Forner en los oscuros años de la lucha antifascista.

\section{Bibliografía}

Altamirano, Sarlo 1997 - C. Altamirano, B. Sarlo, Ensayos argentinos. De Sarmiento a la vanguardia, Buenos Aires 1997.

Chiabra Acosta 1934 - A. Chiabra Acosta, 1920-1932: críticas de arte argentino, Buenos Aires 1934.

Dorival 1942 - G. Dorival, Raquel Forner, Buenos Aires 1942.

El Hogar 1935 - La mujer que desafía el sol de verano... juega con su belle$z a$, "El Hogar", 6 de diciembre de 1935, sin paginar.

Gluzman 2016 - G. Gluzman, Trazos invisibles. Mujeres artistas en Buenos Aires (1890-1923), Buenos Aires 2016.

MARChEL 1925 - L. Marechal, Un cuadro rechazado, "Martín Fierro", 17 de octubre de 1925, p. 177.

La Prensa 1928 - La Prensa, Constituye un conjunto digno de alabanza el XVIII Salón Nacional de Bellas Artes, "La Prensa", 20 de septiembre de 1928, sin paginar.

La Prensa 1930 - La Prensa, Se inauguró ayer oficialmente el XX Salón Nacional de Bellas Artes, "La Prensa", 21 de septiembre de 1930, sin paginar.

La Prensa 1948 - La Prensa, Nuestros artistas plásticos. La pintora Raquel Forner, "La Prensa", 11 de enero de 1948, recorte. Archivo Museo de Artes Plásticas "Eduardo Sívori", Carpeta Raquel Forner.

La Razón 1929 - La Razón, Notas de arte. Nuevo Salón, "La Razón", 19 de septiembre de 1929, recorte. Archivo Fundación Forner-Bigatti.

Lusarreta 1929 - P. de Lusarreta, Memoranda. Recuento de año artístico, "El Hogar", 11 de enero de 1929, p. 53.

LusArreta 1931 - P. de Lusarreta, El Salón de Acuarelistas, "El Hogar", 22 de mayo de 1931, p. 47.

Nochlin 2006 - L. Nochlin, Bathers, Bodies, Beauty: The Visceral Eye, Cambridge 2006 . 
Pagano 1928 - J. L. Pagano, Raquel Forner, "La Nación”, 26 de septiembre de 1928, recorte. Archivo Pagano, Museo de Arte Moderno de Buenos Aires, Carpeta Raquel Forner, folio 3.

Pagano 1940 - J. L. Pagano, El arte de los argentinos, Buenos Aires 1940.

Pollock 1999 - G. Pollock, Differencing the Canon. Feminist Desire and the Writing of Art's Histories, Londres 1999.

QuÉ SuCEDIó EN 7 DíAs 1946 - Una pintora de la mujer doliente, "Qué Sucedió en 7 Días", 17 de octubre de 1946, pp. 34-35.

VAutel 1934 - C. Vautel, Desnudeces veraniegas, "Revista Femenina", 3 de diciembre 1934, p. 1.

WeChSLER 2003 - D. Wechsler, Mujeres del mundo, Buenos Aires 2003.

WeCHSLER 2010 - D. Wechsler, Raquel Forner: El drama, en: R. Amigo (ed.), Museo Nacional de Bellas Artes. Colección, tomo 9, Buenos Aires 2010, pp. 815-817.

Whitelow 1980 - G. Whitelow, Raquel Forner, Buenos Aires 1980.

Whitelow 1983 - G. Whitelow, Raquel Forner. Retrospectiva, Buenos Aires 1983.

Whitelow 1998 - G. Whitelow, Raquel Forner, Buenos Aires 1998.

\section{Summary}

\section{Las bañistas of Raquel Forner: Modern Women}

Argentine painter Raquel Forner (1902-1988) has an outstanding place in the national art historical literature, where her work appears regularly from the founding narrative of critic and art historian José León Pagano in the late 1930s. Her double description as heroine of the avant-garde and as weaver of the antifascist flag has kept partially veiled her active participation in the construction of the various variants of the iconography of the modern woman, a relevant topic in the Argentine art of the 1920s and 1930s. Far from the mourning women that have sustained her entry into the histories of national art, her modern women have strong bodies and powerful gestures. From a series of works associated with the figure of the bather, painted in 1928 and 1929, we will explore the visual construction of a modern femininity, interested in new activities and new scenarios. Far from being a peculiarity of Raquel Forner, this subject permeated the production of other artists who, in various media, dedicated themselves to unfold the visual characteristics of the new feminine appearance and of the social places recently opened to the women. From the celebrated photographer Annemarie Heinrich to the very little known painter Lucrecia Moyano, the concern with this subject was commonplace for many women artists of the 1920s and 1930s. 


\section{Streszczenie}

\section{Las bañistas autorstwa Raquel Forner: współczesne kobiety}

Argentyńska malarka Raquel Forner (1902-1988) zajmuje wybitną pozycję w krajowej literaturze historycznej. Jej twórczość pojawia się tam regularnie od momentu utworzenia narracji założycielskiej stworzonej przez historyka sztuki José Leóna Pagano pod koniec lat 30. XX wieku. Przypisywana jej podwójna rola - bohaterki awangardy i twórczyni flagi antyfaszystowskiej - po części przesłania jej aktywny udział w konstruowaniu różnych wariantów ikonografii współczesnej kobiety, tematu odgrywającego ważną rolę w argentyńskiej sztuce lat 20. i 30. XX wieku. W odróżnieniu od rozpaczających niewiast, które przetrwały w narodowej historii sztuki, jej kobiety mają silne ciała i potężne gesty. $\mathrm{Na}$ podstawie serii prac związanych z postacią kapiacej się kobiety, namalowanych w latach 1928 i 1929, przebadana została wizualna konstrukcja nowoczesnej kobiecości, zainteresowana nowymi działaniami i nowymi scenariuszami. Temat ten, będący początkowo domeną twórczości Raquel Forner, z czasem przeniknął do dzieł innych artystów, którzy - korzystając z różnych mediów - poświęcili się rozwijaniu cech wizualnych nowego kobiecego wyglądu i nowej pozycji kobiety w społeczeństwie. Temat ten był powszechnie podejmowany przez wiele artystek w latach 20. i 30. Odnajdujemy go nie tylko w pracach znanej fotografki Annemarie Heinrich, ale także w dziełach mało znanej malarki Lucrecii Moyano. 